\title{
EVALUATING THE APPLICATION OF HEATING CONDUCTOR SURFACES INSIDE PLASMA SPRAYED COATINGS IN PERMANENT MOLD METAL CASTING PROCESSES FOR LOCAL, NEAR-SURFACE HEAT RELEASE
}

\author{
T. Vossel $(\mathbb{D}$, S. Gor $(\mathbb{C}$, B. Pustal $(\mathbb{C}$, and A. Bührig-Polaczek $(\mathbb{C}$ \\ Foundry Institute, RWTH Aachen University, Intzestraße 5, 52072 Aachen, Germany
}

Copyright $(\subset) 2021$ The Author(s)

https://doi.org/10.1007/s40962-021-00660-1

\begin{abstract}
With casting being a complex process which involves several physical effects and interactions, a wide array of means for influencing such processes exist. Here, the liquid-solid phase change is of utmost importance, as it is a deciding factor for a part's final properties. Especially with today's high critical material property requirements, control of the solidification process is indispensable. For the most part, the cooling of a casting defines its solidification. What determines the cooling process is the heat balance of the system. The foundry industry has been using different

spraying of coatings and the application of heating conductor surfaces have rendered a new concept possible: The integration of heating conductors inside a coating allows for the release of heat in closest vicinity of the melt-mold interface. This paper depicts the use of numerical simulations to investigate the local application of heating conductor layers inside the mold surface coating for a permanent mold casting process and discusses concepts for influencing the heat balance that would not be possible with state-of-the-art cooling channel approaches.
\end{abstract} approaches for influencing the heat balance for a long time. The application of different kinds of coatings with either insulating or heat transfer promoting properties as well as temperature control via cooling channels inside the mold is widely used. Progress in the field of plasma
Keywords: heating conductor, plasma spraying, distortion, heat balance, temperature control

and thermoelectric devices. ${ }^{4,5}$ This includes a coating system concept providing electric heaters inside the sprayed coatings. Usage of the thermal spraying process to fabricate such coating systems has already been discussed in literature. ${ }^{6-9}$ These novel approaches allow for a new thermal balance concept with regard to foundry processes. When planning a casting process, the thermal balance plays an important role as the cooling conditions influence both the solidification, which determines the forming microstructural phases and the final material properties. Temperature control via oil filled cooling channels inside the mold is the state-of-the-art procedure to perform either a preheating of the mold prior to casting or to thermally influence the solidification and cooling of the casting. This in general represents a method with a highly inert reaction time with recent research focusing on optimizing the cooling channel design to improve heat dissipation at hotspot locations. ${ }^{10}$ 

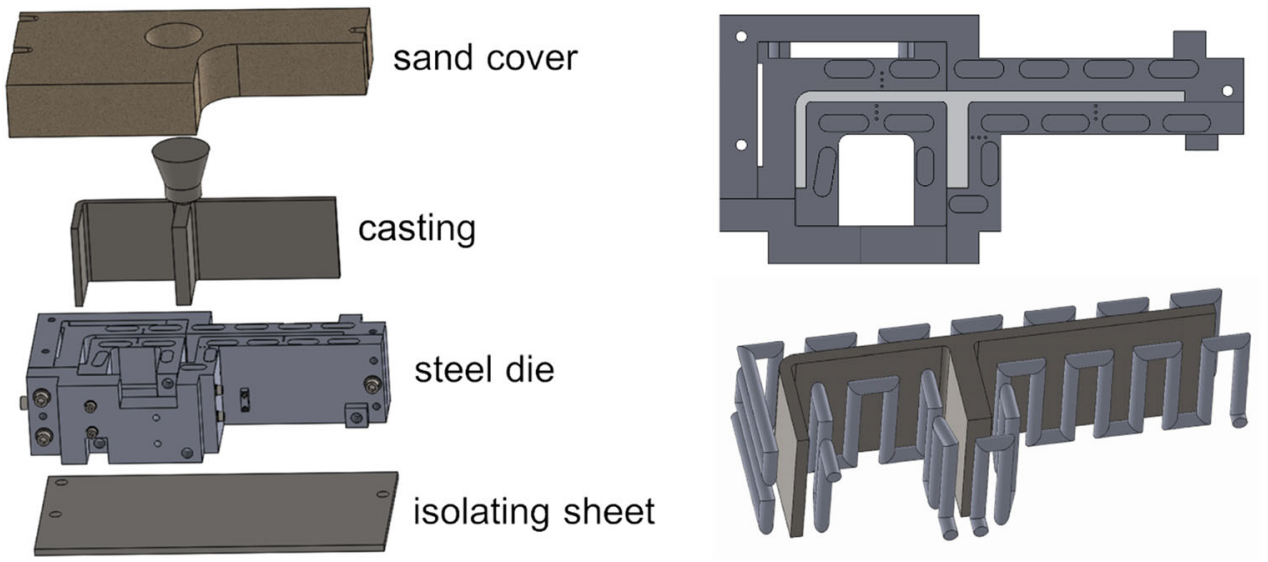

Figure 1. Schematic representation of the experimental setup's four components (left) and the modular die and its integrated cooling channels (right).

Table 1. Chemical Composition of Aluminum Alloy A356 [Mass-\%].

\begin{tabular}{llllllll}
\hline $\mathrm{Si}$ & $\mathrm{Fe}$ & $\mathrm{Cu}$ & $\mathrm{Mn}$ & $\mathrm{Mg}$ & $\mathrm{Zn}$ & $\mathrm{Ti}$ & Other \\
\hline $6.5-7.5$ & 0.12 & 0.02 & 0.05 & $0.3-0.45$ & 0.07 & 0.18 & $\mathrm{Sr}$ \\
\hline
\end{tabular}

This study evaluates the potentials and possibilities of the application of heating conductor layers inside plasma sprayed coatings for permanent mold gravity die casting of an aluminum alloy. The specifications of a $\mathrm{TiO}_{2} / \mathrm{Cr}_{2} \mathrm{O}_{3}$ heating conductor coating system described by Bobzin et al. ${ }^{11}$ are used in order to estimate the thermal surface power densities such a coating can realistically provide. Influence on and potential minimization of a casting's distortion due to thermally induced stresses during solidification and further cooldown represent the focus of the evaluation and serve as preliminary study for the subsequent application of heating conductor layers on an actual experimental setup.

\section{Experimental Setup and Modeling}

This study is based upon an experimental setup developed within the framework of the DFG-funded Collaborative Research Center SFB1120 "Precision Melt Engineering" at the Foundry Institute of the RWTH Aachen University to investigate and influence the casting component's distortion in a gravity die casting process.

An overview of the setup's components is given in Figure 1 . The casting geometry itself consists of an "F"shaped component with a central feeder on its top which is also used as sprue. A modular steel die is built as mold around the casting. It also is fitted with cooling channels around the entire casting cavity subdivided into four independent circuits in order to be able to use an oil temperature control. The base of the mold is made from a ceramic sheet with low heat conductivity functioning as an insulation. The upper mold cover is made out of sand and also contains the feeder/sprue cavity. With the ceramic sheet creating the bottom of the mold and the sand cover acting as the top lid of mold, the main heat dissipation takes place along the casting's contact to the steel die. Aluminum casting alloy A356 is used in this study. Table 1 depicts its chemical composition.

In order to serve as pre-experimental study for the application of heating conductor layers, only certain regions are fitted with them. Their application is meant to result in a strong impact on the components distortion behavior. The "U"-shaped region of the part was identified as region with hindered heat shrinkage due to the mold constraints as the shrinkage of the base line of the " $U$ "-shape should lead to warpage of its two flanks. For this reason, the four junctions of the base line with the two flanks of the "U"-shape were chosen to be fitted with heating conductor layers as shown in Figure 2.

As means of evaluating the distortion of the casting and the influence of heating conductor layers, thermomechanical simulations are performed using the software Abaqus. Figure 3 shows the model that was created to simulate the experimental setup's casting process. The simulation applies a simplification by excluding the simulation of the filling process and assumes a completely filled casting cavity with an initial melt temperature of $720^{\circ} \mathrm{C}$, and the oil used for temperature control is assumed to maintain the chosen temperature level throughout the entire cooling channel disregarding the oil's heating-up which as 

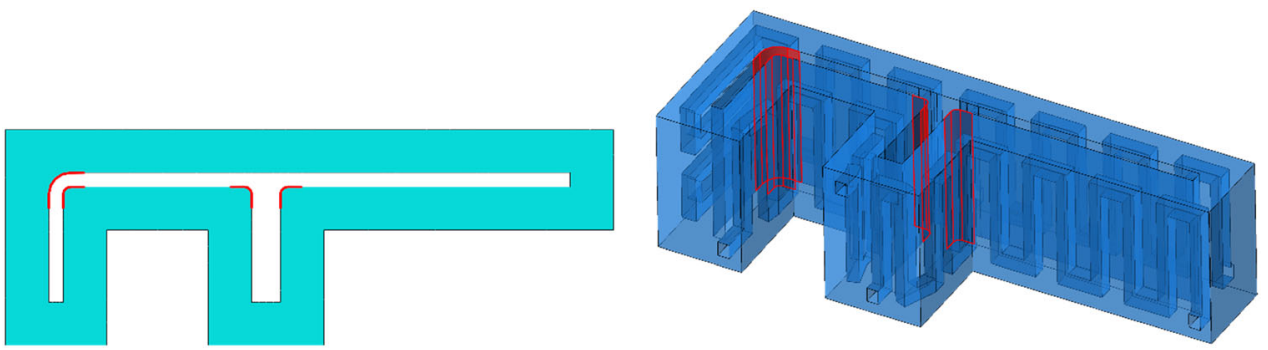

Figure 2. Position of the four junctions with applied heating conductor layers.
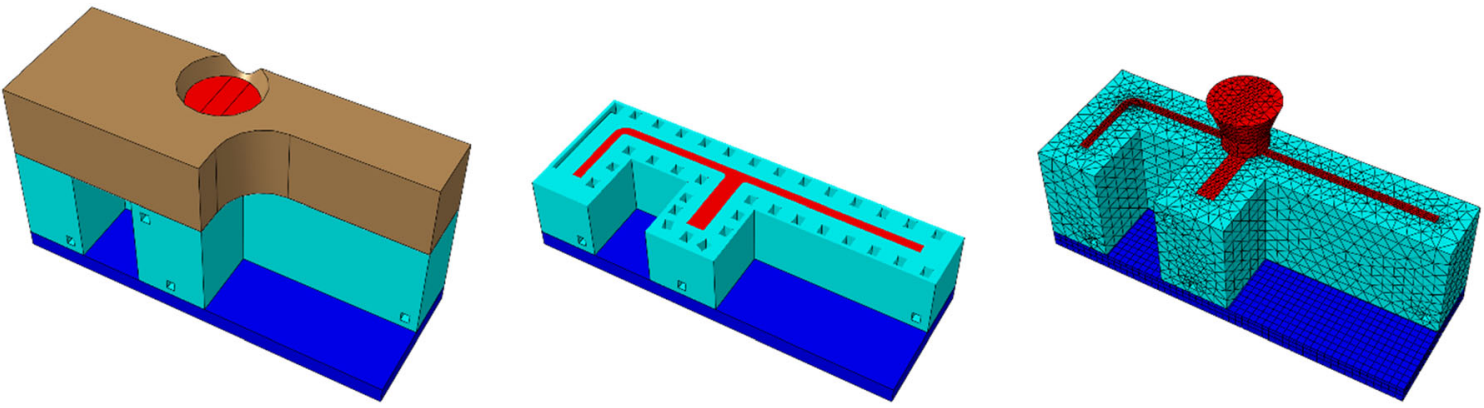

Figure 3. Abaqus thermomechanical simulation model and mesh.

experiments have shown amounts to a $1-2{ }^{\circ} \mathrm{C}$ temperature increase.

Six simulation cases are computed which always include an active oil temperature control as the state-of-the-art way to thermally influence the heat balance. Additionally, the application of the heating conductor layers at all four junctions is an option. The six cases are composed by combining the two oil temperatures of 30 and $300{ }^{\circ} \mathrm{C}$ as well as the two settings of 10 and $30 \mathrm{~W} / \mathrm{cm}^{2}$ for the surface power density of the conductor layers. In order to compare the oil temperature control effect with the influences caused by the heating conductors, a case with oil temperature control only is also simulated. Table 2 gives an overview of these six simulated cases.

The thermomechanical simulation itself is performed in three stages:

- $\quad$ Stage 1: Preheating (30 minutes)
The experimental setup is simulated without the casting component and with active oil temperature control. The preheating stage ends after 30 minutes, and the resulting temperatures and displacements are used as initial conditions for the following solidification simulation.

- Stage 2: Solidification/cooldown inside the mold (5 minutes)

The second stage performs the thermomechanical solidification simulation of the casting inside the mold. The heating conductor layers are turned on at the beginning of this stage. Stage 2 ends after five minutes of solidification and further cooldown of the casting. In terms of the evaluation of the simulation results, the beginning of stage 2 will represent the $0 \mathrm{~s}$ point in process time.

- Stage 3: Demolding and further cooldown with unhindered deformation (2 hours)

All surface contacts of the casting to the mold components are removed. Mold constraints also no longer apply. The

Table 2. Case Overview with the Respective Oil Temperature and Surface Power Density Settings.

\begin{tabular}{llllll}
\hline Case \# & Case label & $T_{\text {oil }}=30^{\circ} \mathrm{C}$ & $T_{\text {oil }}=300 \mathrm{~s}^{\circ} \mathrm{C}$ & $\frac{P_{\text {conductor }}=10 \frac{\mathrm{W}}{\mathrm{cm}^{2}}}{A}$ & $-\frac{P_{\text {conductor }}}{A}=\mathbf{3 0} \frac{\mathrm{W}}{\mathrm{cm}^{2}}$ \\
\hline 1 & $30^{\circ} \mathrm{C}$ & $\mathrm{X}$ & - & - & - \\
2 & $30^{\circ} \mathrm{C} 10 \mathrm{~W}$ & $\mathrm{X}$ & - & - & $\mathrm{X}$ \\
3 & $30^{\circ} \mathrm{C} 30 \mathrm{~W}$ & $\mathrm{X}$ & - & - & - \\
4 & $300^{\circ} \mathrm{C}$ & - & $X$ & $X$ & - \\
5 & $300^{\circ} \mathrm{C} 10 \mathrm{~W}$ & - & $X$ & - & $X$ \\
6 & $300^{\circ} \mathrm{C} 30 \mathrm{~W}$ & - & $X$ & \\
\hline
\end{tabular}


entire casting is allowed to deform freely and contact to air at $20{ }^{\circ} \mathrm{C}$ is assumed to allow for further cooldown to room temperature.

\section{Results}

Prior to discussing the displacement results of the thermomechanical simulations and the influence of the application of heating conductor layers in the gravity die casting process, the changes in temperature development will be discussed. As the conductor layers are only applied at the junctions of the mold (cf. Figure 2), one position on a corner is chosen for further evaluation. As the application of the conductor layers was planned with distortion and mold constraint in mind, the contact pressure result of the simulation is evaluated to identify the parts of the corners with the highest contact pressure. This can be seen in Figures 4 and 5 for the chosen evaluation positions on casting (CP1) and mold (MP1), respectively.

The temperature development on casting and mold turns out as was to be expected. When comparing the two cases of the application of oil temperature control at 30 and $300{ }^{\circ} \mathrm{C}$, the higher temperature setting leads to higher initial mold temperatures and this way lower temperature gradients between melt and mold resulting in a slower cooling of the casting while also approaching the oil temperature as final cooldown state. As for the mold behavior after initial contact with the melt, the mold heats up and peaks at a certain value followed by cooling down to the oil temperature again. The two respective temperature peaks happen after $10.8 \mathrm{~s}$ for the $30{ }^{\circ} \mathrm{C}$ cooling peaking at $184.9{ }^{\circ} \mathrm{C}$ and after $19.1 \mathrm{~s}$ for the $300{ }^{\circ} \mathrm{C}$ cooling peaking at $474.5^{\circ} \mathrm{C}$. Subtracting the initial mold temperature from peak temperature $T_{\text {peak }}$ defines the absolute amount of temperature increase $\Delta T_{\text {peak }}$ as shown in Table 3 . For the $300{ }^{\circ} \mathrm{C}$ temperature setting, the absolute temperature increase is higher.

Considering the influence of the heating conductor layers, the results again change as also was to be expected with the increased amount of generated heat energy slowing down the cooling rates and leading to higher final temperatures representing the stable state consisting of additional heat
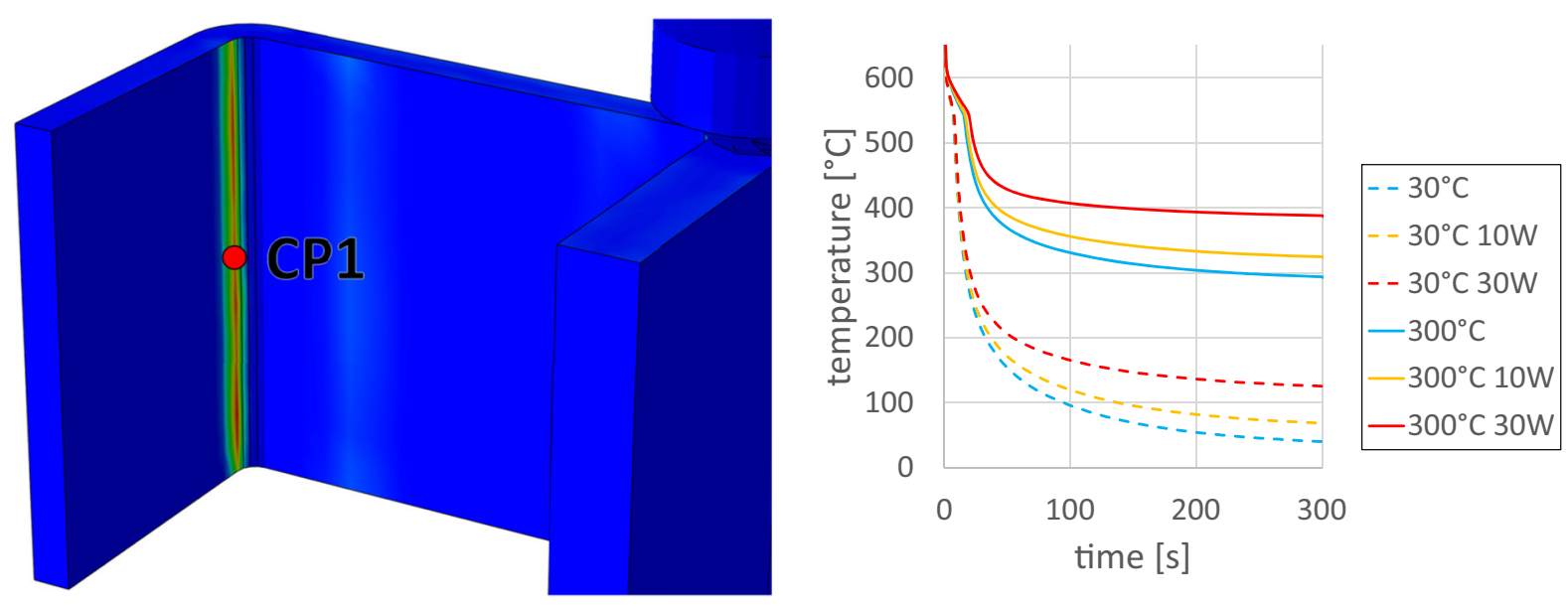

Figure 4. Contact pressure on the casting (left) and temperature development at position CP1 (right).
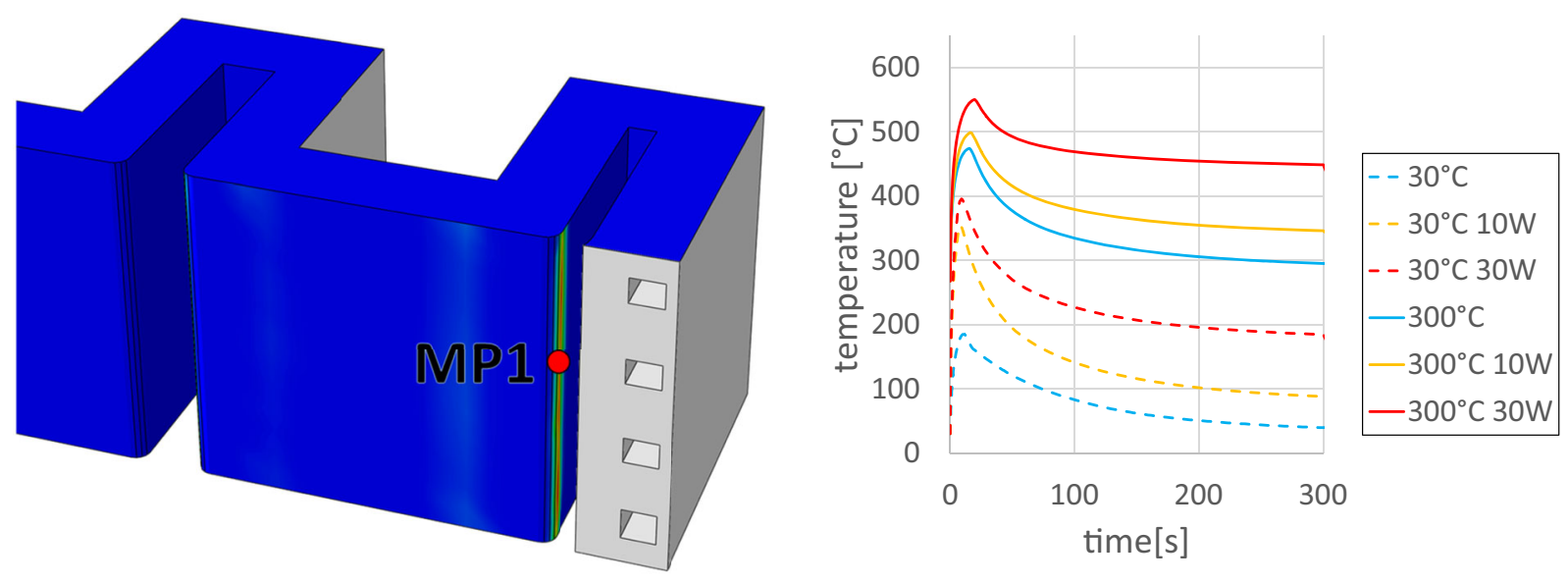

Figure 5. Contact pressure on the mold (left) and temperature development at position MP1 (right). 
Table 3. Final Temperatures After 300 s Process Time and Time, Magnitude and Corresponding Temperature Increase in Mold Peak Temperature at CP1/MP1.

\begin{tabular}{|c|c|c|c|c|c|c|}
\hline & $30^{\circ} \mathrm{C}$ & $30^{\circ} \mathrm{C} 10 \mathrm{~W}$ & $30^{\circ} \mathrm{C} 30 \mathrm{~W}$ & $300{ }^{\circ} \mathrm{C}$ & $300^{\circ} \mathrm{C} 10 \mathrm{~W}$ & $300{ }^{\circ} \mathrm{C} 30 \mathrm{~W}$ \\
\hline \multicolumn{7}{|l|}{ Casting } \\
\hline$T_{\text {final }} @ 300 \mathrm{~s}\left({ }^{\circ} \mathrm{C}\right)$ & 40.4 & 68.7 & 125.6 & 293.9 & 324.6 & 388.1 \\
\hline \multicolumn{7}{|l|}{ Mold } \\
\hline$t_{\text {peak }}(\mathrm{s})$ & 10.8 & 8.2 & 9.1 & 15.4 & 15.9 & 19.9 \\
\hline$T_{\text {peak }}\left({ }^{\circ} \mathrm{C}\right)$ & 184.9 & 354 & 395.5 & 474.5 & 498.9 & 550.4 \\
\hline$\Delta T_{\text {peak }}\left({ }^{\circ} \mathrm{C}\right)$ & 154.9 & 324 & 365.5 & 206.9 & 231.3 & 282.8 \\
\hline$T_{\text {final }} @ 300 \mathrm{~s}\left({ }^{\circ} \mathrm{C}\right)$ & 39.4 & 87.9 & 184.4 & 295.2 & 346 & 448.9 \\
\hline
\end{tabular}
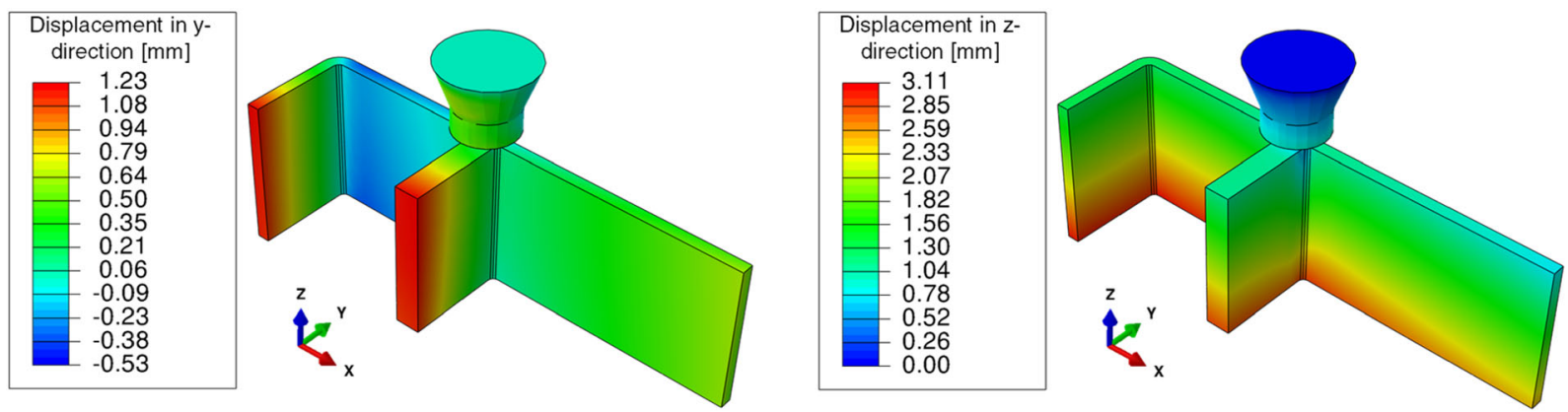

Figure 6. Final displacement of the casting in y- (left) and z-direction (right).

brought into the system via the conductor layers and heat dissipated via the oil cooling. Table 3 shows the respective key temperature values for casting and mold evaluated at position CP1/MP1.

When evaluating the shrinkage and displacement of the "F"-shaped casting, its design especially predetermines shrinkage along the sheet-like spatial dimensions. Figure 6 shows the displacement result for the final, demolded casting in $\mathrm{y}$ - and $\mathrm{z}$-directions for the $30{ }^{\circ} \mathrm{C}$ oil cooled setup. The phase change and cooldown induced volume shrinkage leads to the given one-dimensional shrinkages along the thin walled areas. Here, the feeder and the sand mold surrounding it are responsible for the bottom to top shrinkage of the casting geometry as the sand mold represents the top end of the "F"-shaped casting cavity, while the feeder position inside the sand acts similar to a mounting thus preventing a downwards movement of the entire casting. Air gap formation between the isolating ceramic sheet on the bottom and the casting with ongoing cooldown is the result. With these displacements being the result of the inevitable volume shrinkage during solidification and a negative thermal expansion as the result of further cooldown, a different approach for the evaluation of distortion due to mechanical forces and mold constraints, as well as the respective effects of heating conductor layers, has to be created.

In order to describe the distortion of the casting geometry in consequence of mold constraints and warpage due to the thermal stresses induced via volume shrinkage upon ongoing cooldown, the displacement of the front end of the "U"-shaped part of the casting will be evaluated. As displayed in Figure 7, the corner points of three height levels (lower inner corner, upper inner corner and middle edge position) are evaluated with respect to the displacement in $\mathrm{x}$-direction only. This represents the distortion of the flanks of the "U"-shape which for the chosen casting geometry is the most extensive distortion non-conforming to the desired shape with the created stresses working against the mold constraints. Prior to examining the thermomechanical behavior for all simulated cases, the results for the setup with $30{ }^{\circ} \mathrm{C}$ oil cooling only will be evaluated.

The results for the $30{ }^{\circ} \mathrm{C}$ case in terms of the distortion of the two flanks during cooldown inside the mold are displayed in Figure 8 left. For the O-series of evaluated points representing the inner corner of the outer flank, a uniformly negative displacement can be seen on all height levels. An opposing behavior is given for the I-series representing the inner corner of the inner flank. Here, the developing displacements show a growing positive number with increasing difference between the three height levels as process time proceeds. The final magnitude in displacement between the I- and O-series turns out nearly identical though. Figure 8 right shows the resulting change in distance between the two flanks. As the displacements are measured along the $\mathrm{x}$-axis (cf. Figure 7), a positive flank distance change implies that the "U"-shape widens up, while a negative change in flank distance describes a 


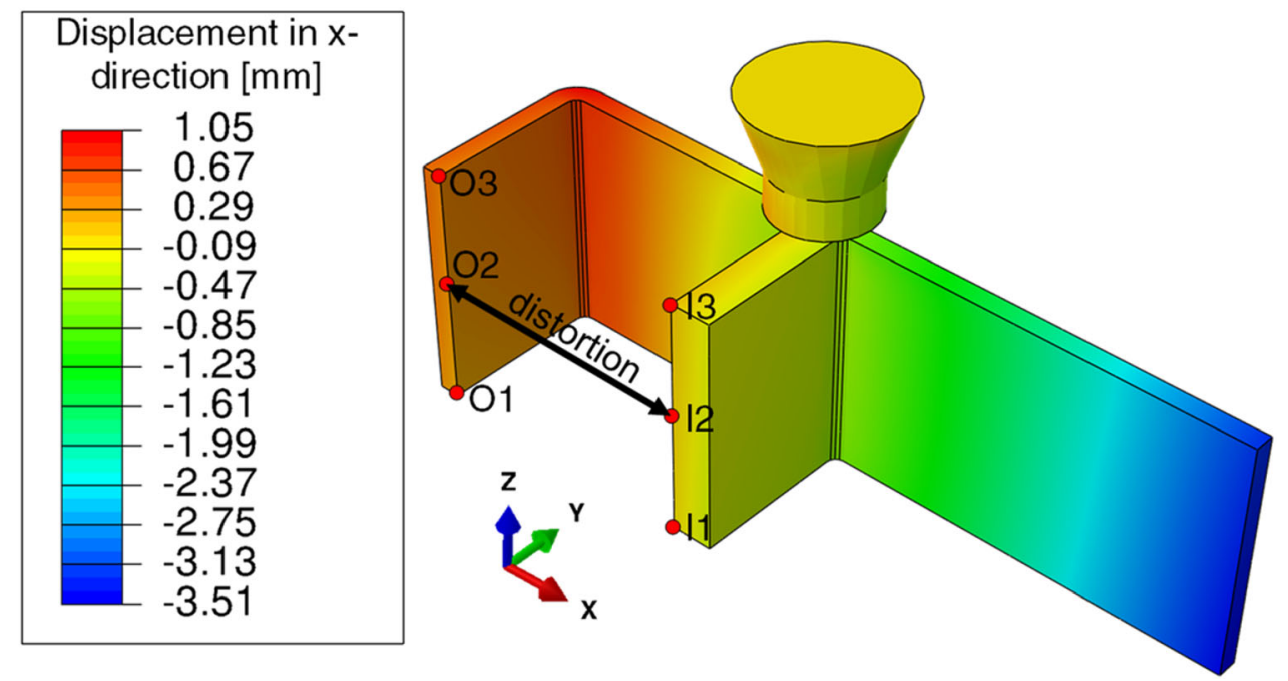

Figure 7. Final displacement in $x$-direction and evaluation points for geometrical distortion.
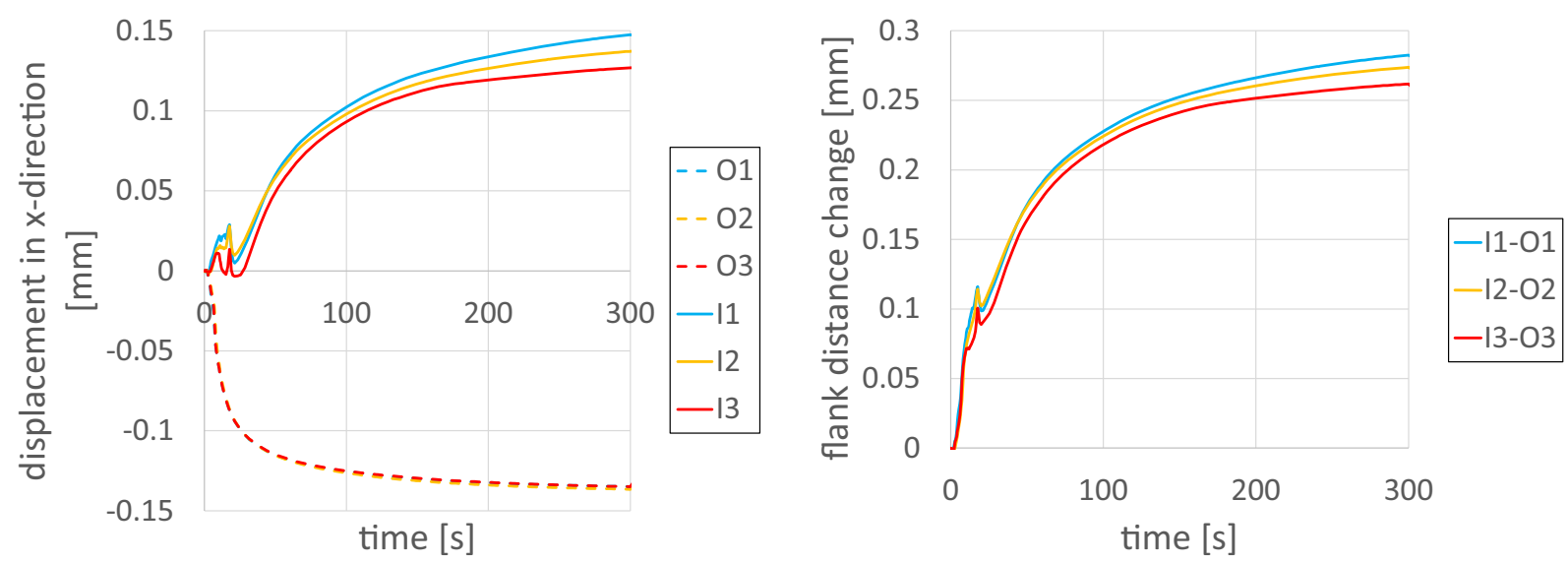

Figure 8. Displacement in X-direction at the evaluation points 01-03 and I1-/3 for the $30^{\circ} \mathrm{C}$ oil cooling only case (left) and the resulting change in flank distance as evaluated on the three height levels (right).
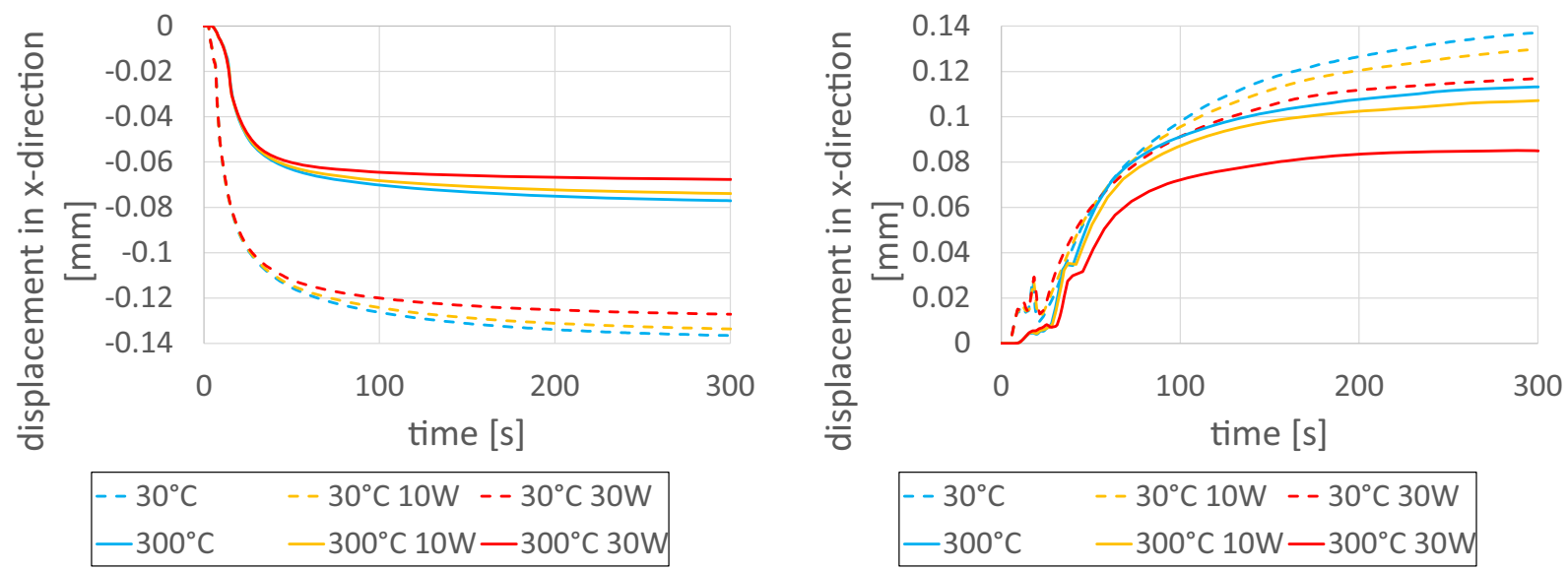

Figure 9. Displacement of the $\mathrm{O2}$ (left) and 12 (right) evaluation point as function of time.

narrowing down of the shape. The inverted sign of the Iand $\mathrm{O}$-series and the nearly identical displacement magnitudes lead to a quasi-uniform widening up of the "U"- shape as both flanks move away from each other. This generally identical behavior on all three height levels also occurs for the other simulated cases. For this reason, the 


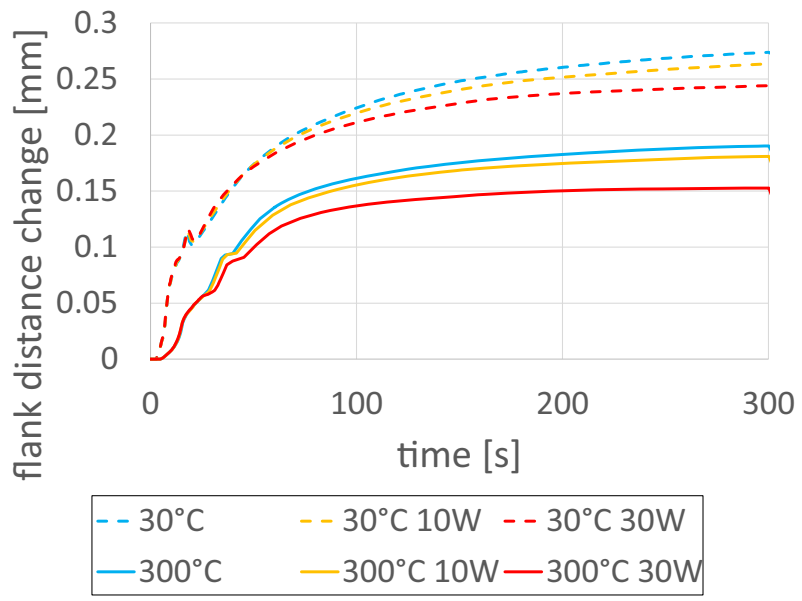

Figure 10. Development of 12-02 flank distance change during in-mold process stage.

following examination will discuss the I2-O2 height level only in order to describe the average displacement behavior.

Figure 9 shows the displacements of the $\mathrm{O} 2$ and I 2 evaluation points for all simulated cases (cf. Table 2) during the casting's cooldown stage inside the mold as function of time. A significant influence of both the $30 / 300{ }^{\circ} \mathrm{C}$ oil temperature and the optional heating via the $10 / 30 \mathrm{~W} / \mathrm{cm}^{2}$ conductor layer setting can be seen. For the $\mathrm{O} 2$ position, the oil temperature has the bigger impact. Applying the lower $30^{\circ} \mathrm{C}$ oil temperature leads to a more rapid development of distortion effectively doubling the displacement values in comparison with the $300{ }^{\circ} \mathrm{C}$ setting. The additional use of heating conductor layers slightly reduces the displacement of the outer flank. An inverted tendency is present for the I2 position. Here, the effect of higher displacements occurring faster with decreased oil temperature is also present but with a lower absolute impact in terms of the magnitude in displacement. The application of conductor layers on the other hand has a strong influence when being combined with the $300{ }^{\circ} \mathrm{C}$ oil cooling resulting in significant slower/lower distortions. Combining both displacement results into the flank distance is displayed in Figure 10. The effect of a widening up " $U$ "-shape still is present with the choice of oil temperature having the strongest influence on the distortion.

Analysis of these results displays the influences of the inmold effects on a casting with respect to the applied temperature control. The effect of displacements developing faster with lower oil temperature simply is the consequence of a faster cooldown which with respect to time leads to thermal stresses rising faster thus leading to increased distortion. Keeping the system at a certain temperature limits the stresses and thus the displacements where in the given case a change from 300 to $30^{\circ} \mathrm{C}$ oil temperature leads to a 50-100\% increase in in-mold displacement. Heat added via the heating conductor layers consequently forms an influence opposing the heat extraction resulting in slower cooldown and thus lower displacements. Here, it can be noted that the local heat sources of the conductor layers already have a significant impact when only being activated in the 2 nd process stage and not being part of the preheating phase. The concept of thermally influencing only the four junctions of the mold in order to significantly influence the "U"-shape distortion also is shown to be a valid approach. In addition to that a strong and immediate influence on the thermal balance unlike the inert oil temperature control concept (hence the 30 minutes preheating for the $300{ }^{\circ} \mathrm{C}$ oil temperature control needed to ensure that the mold has heated up to a stable, uniform level) is implied. Including the conductors during preheating leading to increased local mold temperatures could increase their influence on both heat balance and distortion even more.

With the displacements being dependent on the temperature as consequence of the thermal stress formation, the evaluation of the displacement development over time only gives a limited impression of this dependency. For this reason, Figure 11 displays the distortion as function of the local temperature present at the $\mathrm{O} 2$ and $\mathrm{I} 2$ evaluation positions. A distinct difference in behavior can be identified between the outer, thinner flank and the inner flank with higher wall diameter. For the $\mathrm{O} 2$ position, the displacement development carries resemblance with a hysteresis curve as quasi-identical distortions are present below $400{ }^{\circ} \mathrm{C}$ just as for temperatures above $500{ }^{\circ} \mathrm{C}$ independent of the simulated case. In-between a higher oil temperature leads to a faster increase in displacement. This way the displacement development only differs in a temperature range from 400 to $500{ }^{\circ} \mathrm{C}$ for the $\mathrm{O} 2$ position with respect to local temperature.

The I 2 position, however, shows a different behavior. Here, the oil temperature represents the main influence with the lower $30{ }^{\circ} \mathrm{C}$ oil temperature delaying the strong, quasilinear increase in displacement from a start at around $500{ }^{\circ} \mathrm{C}$ to $400{ }^{\circ} \mathrm{C}$ local temperature. Opposing influences can be seen for the heating conductor influence. When applied with a $30{ }^{\circ} \mathrm{C}$ oil temperature control, the strong quasi-linear displacement increase is slightly promoted, while the application with $300{ }^{\circ} \mathrm{C}$ oil temperature control shifts the displacement increase to slightly lower temperatures while also decreasing the rate of distortion increase. As a conclusion, the wall diameter has to be seen as decisive factor determining if thermal influences can play a relevant role in the formation of distortions for in-mold castings.

In order to examine the influence of oil temperature control and heating conductor layers in terms of the final state of a casting, the stage of demolding after 5 minutes of process time is simulated with all mold constraints and surface contacts removed and the total casting being in contact 

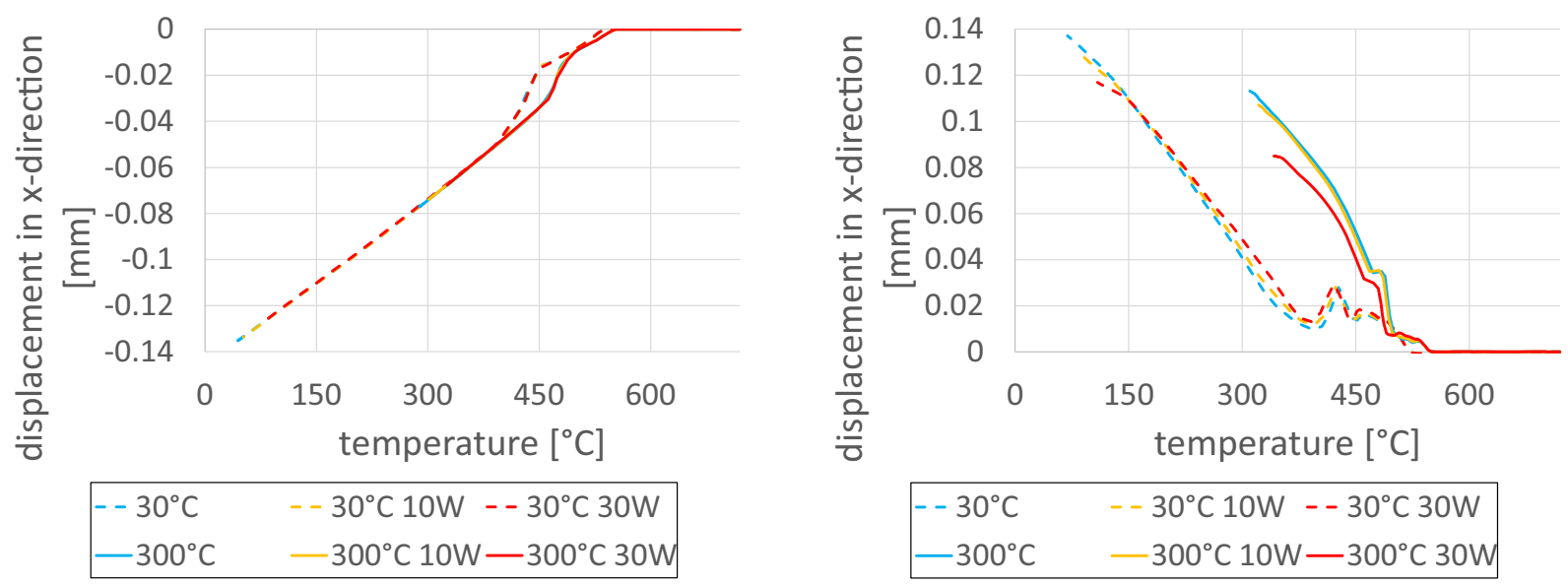

Figure 11. Displacement of the $\mathrm{O2}$ (left) and 12 (right) evaluation points for different case settings as function of temperature.
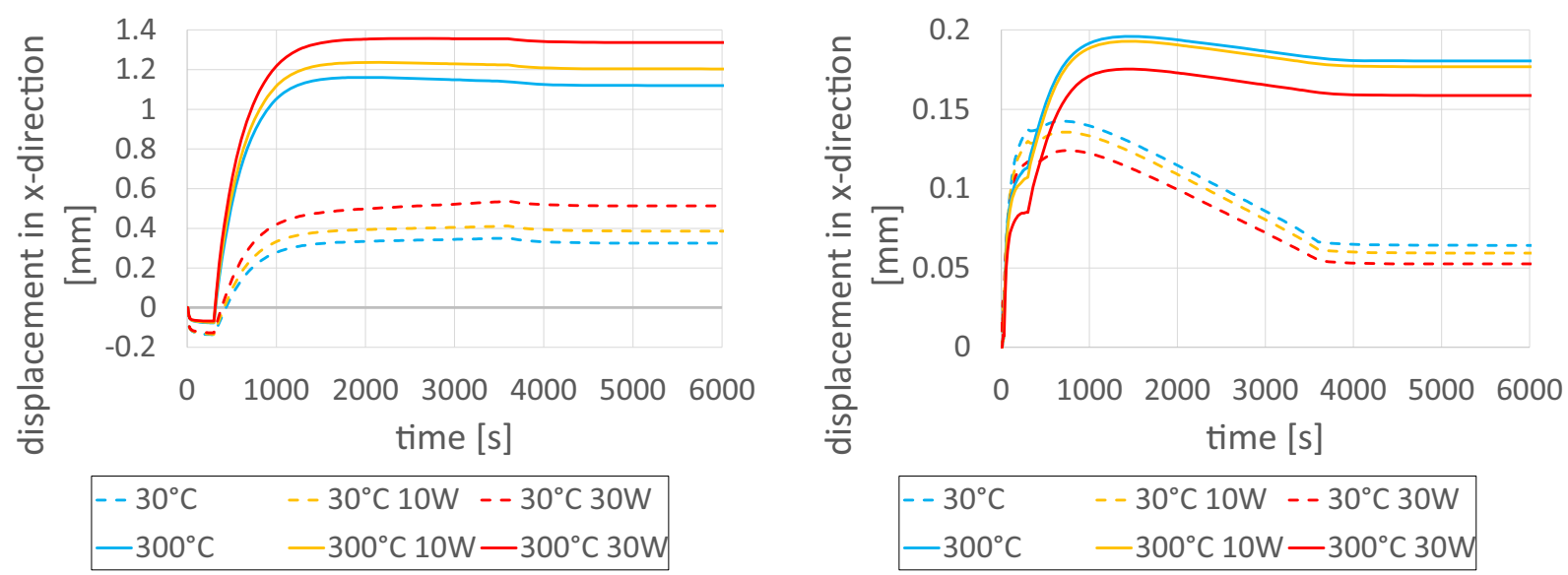

Figure 12. Displacement development of the 02 (left) and 12 (right) evaluation points for in-mold and demolded process stage.

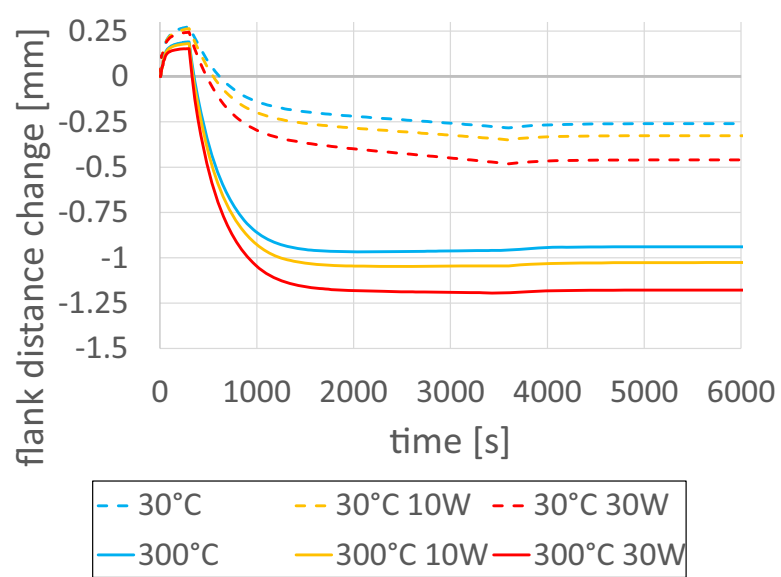

Figure 13. Development of 12-02 flank distance change of the casting during in-mold and demolded process stages.

with air at $20{ }^{\circ} \mathrm{C}$ temperature. Under these cooling conditions, it takes around 1.5 hours until the entire casting has cooled down to the surrounding air temperature. Figures 12 and 13 thus display the already discussed development of O2/I2 displacement and flank distance change now extended to time frames beyond the in-mold cooldown stage ending after $300 \mathrm{~s}$ of process time. Removing the mold constraints has a significant influence on the casting's distortions as without counter-forces exerted by the steel die the casting's internal stresses can relax freely resulting in warpage reaching levels one order of magnitude higher than during the in-mold stage. As for the $\mathrm{O} 2$ and $\mathrm{I} 2$ evaluation positions, demolding has completely different effects on the respective distortions. For the I2 position, demolding results in distinct distortion behaviors depending on the chosen oil temperature. $30{ }^{\circ} \mathrm{C}$ oil temperature leads to a declining raise in displacement which peaks at around $600 \mathrm{~s}$ of process time. From this point onwards, a quasi-linear decrease in displacement takes place until reaching final values after around one hour. $300{ }^{\circ} \mathrm{C}$ oil temperature on the other hand leads to a strong raise in distortion immediately after demolding peaking at values effectively doubling the displacement values after about 1200 s. With ongoing time and cooldown, the displacement reduces slightly until reaching final values after 
around $3900 \mathrm{~s}$. When comparing the final distortion values, choosing the 300 over the $30^{\circ} \mathrm{C}$ oil temperature triples the final displacements. Additional heat input via conductor layers has the uniform tendency to reduce the occurring displacements with only minor changes for the $10 \mathrm{~W} / \mathrm{cm}^{2}$ heating setting and around $10 \%$ displacement reduction with a $30 \mathrm{~W} / \mathrm{cm}^{2}$ heating when comparing with the purely oil cooled case.

Evaluation of the $\mathrm{O} 2$ position shows a completely different behavior. While the outer flank moves in negative $\mathrm{x}$-direction during the in-mold cooldown stage, removal of the mold constraint leads to a strong relaxation in the positive $\mathrm{x}$-direction with displacements changing from a minimum of about $-0.137 \mathrm{~mm}$ to a peak displacement of up to + $1.36 \mathrm{~mm}$. Strong stresses inside the junction of the outer flank of the "U"-shape and a lower wall diameter than for the inner flank lead to this strong response to demolding. The oil temperature has the main influence on the extent of positive $\mathrm{x}$-direction displacement. Applying a $300{ }^{\circ} \mathrm{C}$ oil temperature once again triples the final distortion values in comparison with the $30{ }^{\circ} \mathrm{C}$ setting. Usage of heating conductor layer has an opposing effect than for the I 2 position. For the $\mathrm{O} 2$ evaluation point, the increased heat input increases the displacements. A $10 \mathrm{~W} / \mathrm{cm}^{2}$ setting increases the final distortion by $10-20 \%$ while using the $30 \mathrm{~W} / \mathrm{cm}^{2}$ setting increases the displacement by $20-60 \%$.

This way the final distortion of the gap between the two flanks leads to a narrowing down as the negative flank displacement values displayed in Figure 13 show. Overall, the oil temperature represents the primary influence on the flank distance with an about four times higher displacement value for the $300{ }^{\circ} \mathrm{C}$ oil temperature in comparison with the $30{ }^{\circ} \mathrm{C}$ setting. Using additional heating conductors has a nearly identical effect for both oil temperature settings with a final displacement increase in around $0.08 \mathrm{~mm}$ for the $10 \mathrm{~W} / \mathrm{cm}^{2}$ conductor setting and an increase in about $0.22 \mathrm{~mm}$ for the $30 \mathrm{~W} / \mathrm{cm}^{2}$ setting. The differences in distortion magnitude between the $\mathrm{I} 2$ and $\mathrm{O} 2$ position can be explained via the differences in the respective casting section thicknesses which is lower for the $\mathrm{O} 2$ position leading to a stronger impact of the relaxing forces.

\section{Conclusion}

The influence of oil temperature control and the additional application of heating conductor layers on distortion of a gravity die casted part was examined by evaluating the simulated, one-dimensional displacement of the $\mathrm{I} 2$ and $\mathrm{O} 2$ evaluation positions. This approach follows the underlying idea that the "U"-shaped region of the casting features the biggest stresses and mold constraints. For this reason, heating conductor layers were applied at these regions' junctions. With the flanks of the "U"-shape acting as a lever amplifying the distortion effects at the junctions, the highest measurable distortion response as result of the changes in heat balance should be present here. It is shown that the choice between 30 and $300{ }^{\circ} \mathrm{C}$ oil temperature represents the major factor of the two methods for thermally influencing the heat balance with the biggest impact on displacement change. Due to the complexity of the process and the examination of distortions for both the casting remaining inside the mold and demolding the casting, no general result for the influences of oil temperature control and heating conductors can be given as both feature opposing influence tendencies depending on the process stage. While in-mold, increasing the oil temperature decreases the occurring displacements. For the demolded case on the other hand, increasing the oil temperature leads to also increasing distortions. The same opposing tendency inversely applies for the application of heating conductors. Here, an increased energy input via heating layers at the junctions lowers the displacements of the flanks for the in-mold stage, but the final demolded warpage increases for additional heat generation at the heating conductors. The reason for this probably lies within preventing further cooldown which represents the primary factor for avoiding displacement in the in-mold stage. When releasing the mold constraints and slowly letting the casting cooldown due to air contact, it probably is advantageous for warpage minimization to cooldown the casting inside the mold far as far as possible so the thermally induced stresses to a certain extent already have been relaxed in form of plastic deformations constrained by the metal die.

In general, the application of heating conductor layers in a permanent mold casting process has proven to be a valuable new possibility to influence a system's heat balance. One of the main advantages lies within the possibility to not only have a locally restricted influence if so desired, but also have an immediate heat generation at the casting/mold interface due to the application as a coating. This provides new possibilities for thermally influencing casting processes without the inert behavior featured by state-of-theart oil temperature control concepts which cannot deliver a strongly localized, near interface, fast heat energy input.

\section{Outlook}

The presented approach to examine the possibilities of the application of heating conductor layers represents a first step for evaluating of the respective influences and effects. The analysis of the one-dimensional displacements of the chosen evaluation points allows for a quick and clear assessment of the different cases but is limited in depicting the actual warping process in its entirety. In order to perform a more comprehensive analysis, the discussion of a distance between two points is not sufficient as the threedimensionality of the process is more complex than a onedimensional distance between two points can express. A 
follow-up evaluation thus has to think of form factors or other spatial relations which can describe the casting geometry and its changes in more detail. In addition to that, the simulation scope has to be extended when trying to predict temperatures and distortions for industrial processes. A multi-cycle casting process should be considered as well as the simulation of the mold filling process.

Furthermore, the integration of heating conductors in the preheating process could be a valuable concept. As the oil temperature, which was successfully identified as the major influence, determines the initial temperature of the melt/mold contact, the use of heating conductor during preheating would allow for influencing the initial mold temperature both significantly and locally. It could be possible to achieve higher mold temperatures than it is possible with state-of-the-art oil temperature control as oils usually evaporate at temperature of $370{ }^{\circ} \mathrm{C}$ which has to be prevented. Being able to specifically heat a certain mold area near the interface would allow for higher initial mold temperatures without exceeding the oil temperature limits.

\section{Acknowledgements}

The presented investigations were carried out at RWTH Aachen University within the framework of the Collaborative Research Center SFB1120236616214"Bauteilpräzision durch Beherrschung von Schmelze und Erstarrung in Produktionsprozessen" and funded by the Deutsche For-schungsgemeinschaft e.V. (DFG, German Research Foundation). The sponsorship and support is gratefully acknowledged.

Open Access This article is licensed under a Creative Commons Attribution 4.0 International License, which permits use, sharing, adaptation, distribution and reproduction in any medium or format, as long as you give appropriate credit to the original author(s) and the source, provide a link to the Creative Commons licence, and indicate if changes were made. The images or other third party material in this article are included in the article's Creative Commons licence, unless indicated otherwise in a credit line to the material. If material is not included in the article's Creative Commons licence and your intended use is not permitted by statutory regulation or exceeds the permitted use, you will need to obtain permission directly from the copyright holder. To view a copy of this licence, visit http://creativecommons. org/licenses/by/4.0/.

\section{Funding}

Open Access funding enabled and organized by Projekt DEAL.

\section{REFERENCES}

1. A. Bührig-Polaczek, W. Michaeli, G. Spur, Handbuch Urformen (Carl Hanser Verlag, München, 2014)

2. N. Wolff, J. Krampe, U. Vroomen, A. BührigPolaczek, Comparison of the thermal properties of industrially used die coatings and a plasma sprayed YSZ coating for gravity die casting applications. AFS Trans. 127, 309-314 (2019)

3. C. Mitterer, Ü.F. Holler, D. Heim, Application of hard coatings in aluminium die casting - soldering, erosion and thermal fatigue behaviour. Surf. Coat. Technol. 125(13), 233-239 (2000)

4. J.P. Longtin, L. Zuo, D. Hwang, G. Fu, M. Tewolde, Y. Chen, S. Sampath, Fabrication of thermoelectric devices using thermal spray: application to vehicle exhaust systems. J. Therm Spray Tech 22, 577-587 (2013)

5. K. Bobzin, M. Öte, M.A. Knoch, X. Liao, C. Hopmann, P. Ochotta. Investigation of influencing factors on the transfer of wire arc sprayed zn coatings for the metallization of plastic parts. In: International Thermal Spray Conference, pp. 24-29 (2016)

6. M. Prudenziati, G. Cirri, P.D. Bo, Novel HighTemperature Reliable Heaters in Plasma Spray Technology. J. Therm. Spray Tech. 15, 329-331 (2006)

7. D. Michels, J. Hadeler, V.J.H. Lienhard, High-heatflux resistance heaters from VPS and HVOF thermal spraying. Exp. Heat Transf. 11(4), 341-359 (1998)

8. M. Prudenziati, Development and the implementation of high-temperature reliable heaters in plasma spray technology. J. Therm. Spray Tech. 17, 234-243 (2008)

9. M. Prudenziati, M.L. Gualtieri, Electrical properties of thermally sprayed Ni- and Ni20Cr-based resistors. J. Therm. Spray Tech. 17, 385-394 (2008)

10. C. Hopmann, T. Schneppe, M. Theunissen, A. BührigPolaczek, N. Wolff, Investigation on the transferability of algorithms for the numerical optimization of cooling channel design in injection molding on metal gravity die casting. Mat.-wiss. u. Werkstofftech. 48, 1220-1225 (2017)

11. K. Bobzin, M. Öte, M.A. Knoch, I. Alkhasli, Temperature distribution on thermally sprayed heating conductor, In: IOP Conf. Series: Materials Science and Engineering 480 (2019)

Publisher's Note Springer Nature remains neutral with regard to jurisdictional claims in published maps and institutional affiliations. 